\title{
COMPETENCE DEVELOPMENT SUPPORTED BY DIGITAL MEANS IN A KNOWLEDGE- INTENSIVE COMPANY
}

\author{
The Case of TietoEnator
}

Ari Alamäki and Kalle Mäkinen

TietoEnator Oyj, Arabianranta 6, FIN-00560 Helsinki, Finland

\begin{abstract}
This paper reviews practical experiences in digitalizing competence development in a large corporation. Many practical experiments have shown that building learning portals and purchasing off-the-shelf courses are easier tasks than creating demand and understanding new ways of learning at the grassroots level of an organization. Digital competence development should be seen as a strategic approach rather than as a new operational tool. It is a change process that requires successful showcases, careful plans and strategic steps in the right direction. Blended learning models, which support informal learning at the workplace, should replace older classroom-based learning paradigms. Only in this way can corporations bring their learning into the knowledge-intensive era.
\end{abstract}

Key words: competence development, e-learning, organization

\section{INTRODUCTION}

Investing in people is a much more complicated process than investing in new machines and production lines. In developing human capital in corporate environments we are dealing with many human factorsorganizing courses and seminars are only the tip of the iceberg in building organizational learning. The nature of organizational learning is changing because the development of technology is causing industrial countries to evolve from industrial societies to post-industrial societies. Science-based technology and an emphasis on information and knowledge are typical of a post-industrial society (Bell, 1976). Current inventions, products and 
services are increasingly created as a result of scientific research and development in multidisciplinary teams and social networks, a phenomenon which differs from that which was typical to an industrial society.

The interaction between higher-order thinking skills and scientific knowledge is emphasized more than ever in developing new products and in creating new services (Alamäki, 2000). This process of change should be more clearly reflected in the present ways of designing learning programs and competence development strategies at all levels of knowledge-intensive companies. Technological development, control, and utilization have been, and still are, directly dependent on our abilities to innovate and solve problems; technology is, and will continue to be, a human activity. We must educate employees who have the ability to learn by doing, solve ill-defined problems, and collaborate in a social environment. Therefore, we should be able to support both formal and informal learning at the workplace.

This article focuses on the possibilities provided by digital means in building a learning organization in knowledge-intensive companies. In this article, we define digital competence development as a continuum ranging from separate instruction-centered training events to a longer-term and effective learning strategy and process supported by digital means. When digital competence development is understood as a strategic issue in competence development, its benefits also become clearer. We consider digital competence development a strategically important aspect in an organization's learning and business development. While information management only gathers information, digital competence development makes collective knowledge creation and organizational learning a reality. The objective of digital competence development is to support the existing training and competence management processes in the organization.

\section{LEARNING IN KNOWLEDGE INTENSIVE COMPANIES}

The ability to innovate and learn new knowledge and skills has become a priority of corporations, institutions and nations. Therefore, many companies seek new ways to respond to the stiffer competition caused by the globalization of markets. It is believed that so-called digital competence development makes training and learning processes more efficient and quicker.

In the industrial era, training was often removed from the workplace and situated in training centers. According to research (Lave, 1988), adults' learning is functional and often tied to the situation where it takes place (Hutchins 1995). If a substantial boost in competence development is 
desired, a lot of emphasis should be placed on informal learning in the workplace. For this reason, digital learning solutions should support both classroom training and informal learning at the workplace.

These digital learning solutions have many advantages compared to the older classroom training paradigm (e.g., Alamäki \& Luukkonen, 2002): Web-based learning solutions are continuously available to users; they adapt better to the needs of knowledge; the content can be updated anytime during the life span of the learning process; the content can be personalized for different target groups and business units; usage of the learning solutions can be tracked by reporting tools. Success in global competition often requires the use of modern digital technologies in competence development, namely digital competence development.

Many companies, however, have failed in their digital competence development initiatives, although there are several success stories as well. Poorly designed learning content is a major reason for weak learning results and poor usage statistics. 'Electronic reading' is not 'electronic learning', nor does abstract text transfer to effective working practices without concrete illustrations and without involving the learner. Learners are only interested in what they feel, see and can do on the computer screen. Too many companies have begun building solutions without understanding pedagogical and media expertise; learning content should have a direct and practical link to learners specific learning needs and motivation.

\section{CASE DESCRIPTION: TIETOENATOR}

TietoEnator is a leading provider of value-added IT-services, with 13,000 employees in over 20 countries. It specializes in developing and maintaining business-related IT-systems in a networked world. TietoEnator offers consulting services, software development and integration, usage and web administration, customer product development and program services. These services are based on a strong knowledge of our customers' business areas and technical know-how. TietoEnator offers e-learning products and services for their customers as well.

In the following we describe how TietoEnator built its corporate-level infrastructure for digital competence development. Based on these experiences, we review the digitalizing of competence development at a general level since experiences and lessons to be learned are quite similar in many companies. 


\section{HOW DID TIETOENATOR BEGIN ITS DIGITAL COMPETENCE DEVELOPMENT?}

At the end of the last century, a need to promote learning in the areas of new technologies was recognized. Electronic learning was seen as a tool that could increase competencies needed in building high value-added ITservices. At the beginning of 2000, TietoEnator began a project named TietoEnator Academy (TEA), which consisted of several sub-projects. Each sub-project had its role in the TEA project. The sub-projects focused on tasks, such as the building of a learning management system, content production for customized courses, user management and invoicing system, creation of networks with universities and other academic institutions, knowledge management and support services.

In project management, TietoEnator's own project management system, PPS, was used to manage and control the functioning of different subprojects. The TEA project was controlled by a steering committee. The Content Reference Group was responsible for the content and the collection of learning needs from the line organizations. TietoEnator's ISF-system, which was originally built for the user management and invoicing in online services, took care of user management and internal invoicing. The learning management system (LMS) in the learning portal was also TietoEnator's own solution, which included content management systems, reporting and authoring tools as well as a discussion forum for each content topic. The LMS with user management and invoicing systems, the first customized courses and project organization itself were set up in a short period of time compared to corresponding projects in other international companies.

TEA was launched at the end of 2000. Employees were informed by email and via other marketing campaigns. The course hierarchy consisted of three levels: Basic level courses, Business Area-specific courses and Expert level courses. The first courses were basic level courses aimed at all employees, and they were created by pedagogical and media experts at TietoEnator. Substance experts wrote the screen texts, but other external expertise was not needed in production. The instructional design was based on theoretical and practical illustration with orientation animations about the main issues presented in learning material. Most of them also had pre-tests and final tests, and after completing a course, users could print a diploma with their final test scores.

During the first year, off-the-shelf courses from well-known international companies were purchased in addition to our own content production. The courses focused on programming, computer skills, IT-architectures, languages, marketing, sales and internal processes. 


\section{LESSONS LEARNED OVER THREE YEARS}

Experience showed that customized courses with high-quality content presentation were much more successful than the large libraries of off-theshelf courses. Poorly designed content does not motivate anybody. The pedagogical quality of courses is very important for the transfer of learning: knowledge is not an object that can be transferred from the computer screen to the brains of learners. It is obviously important to deliver useful knowledge, but it has to be linked to concrete examples and practical illustration in order to activate learners' mental processes. This is the only way that the course content supports the effective building of internal schemas or mental models, i.e. people learn by applying new knowledge in meaningful contexts.

The decisions, strategies and operative work that will be used should be created or at least evaluated by experts in digital competence development. It is also important to use pedagogical experts in planning solutions and guidelines. The responsible parties should understand how employees actually learn and how to design and implement pilot projects in practice. For example, programmers and other IT experts have acquired their knowledge by reading manuals, talking with colleagues, accessing discussion areas and using the Internet's search engines as an "information bank". Therefore, it is important to understand the types of learning to which digital means can be applied, what the limitations of digital means are, and what the business benefits are to the organization.

The digitalizing of competence development is not just "an IT-project". Purchasing LMS or any technological system does not digitalize a training process. The definition of vision, strategy and operative processes for digital competence development is more important than many managers believe. They direct development actions, steps and speed of progress - we can seldom bring our organizations into the digital age in one year. Therefore, the nature and structure of the organization, its core processes, learning and management culture and many other issues determine the strategic steps for digitalizing competence development. In fact, they are starting points for the e-learning strategy of an organization.

"If you build it, they will come" does not work in competence development. The digitalizing of competence development requires change management. According to our experiences, it is advisable to start with small steps in the right direction that focus on the creation of basic understanding in the business units. The human mind is conservative and organizations run their businesses with established processes - tacit knowledge has a central role in most activities. People do not easily change or reject their routine work practices even if they know new practices are more beneficial than 
existing ones. For example, Agryris (1992) reviews this matter in his model about single and double-loop learning in organizations. Issues, which do not require change in determining factors of organization, can be easier to realize. As Senge (1990) says, "if you push the organization, it pushes back". Therefore, during the time you build supply, you must simultaneously create demand and basic understanding at the grassroots level of the organization. This can be done by successful business cases and concrete examples.

Why build expensive and fragmented learning environments if the corporate intranet is already usable as a delivery channel? Fragmented and overlapping IT-systems cause extra costs for the organization (Weill \& Broadbent, 1998). For example, the current learning portal at TietoEnator is part of the new intranet system. What learners are mostly asking for is relevant learning content; self-study courses can be delivered and users and content can be managed using the corporate intranet. Collaboration tools, however, have a different purpose than self-study material and are therefore often more individual systems, such as ASP-services linked to the corporate intranet. Hence, in choosing technologies we need to keep pedagogical models in mind; different pedagogical models often require different technological decisions.

In bringing competence development into the digital age, managers are in a key role. Managers' involvement and personal example to their subordinates as e-learners are essential success factors. For example, in one certain business unit, managers - if only a few - displayed their own final test diplomas beside the door of the office as an example to their subordinates. The managers' example was found to be very important in the rollout of digital competence development initiatives in the business units.

\section{HOW TO DEVELOP A LEARNING ORGANIZATION BY DIGITAL MEANS}

In designing learning solutions that support learning in the right form, at the right time and in the right place, we need to pay attention to both informal and formal learning at the workplace (e.g., Alamäki \& Luukkonen, 2002; Masie, 2002; Rosenberg, 2001). In designing and creating effective learning solutions, we have to know how people really learn and how their expertise develops in everyday situations. In fact, it is a mistake to focus only on the results of competence surveys, which only reveal what people need to know. For example, although the title of a course may correspond to competence needs, its form of knowledge may not necessarily be applicable to the real working situation. 
Since digital competence development is culturally often a new element in the competence management strategy, it turns attention on change management. It is important to build "show cases" or "corporate quick wins" soon after the coaching, definition and other planning. Business unit managers and their subordinates require concrete examples and hands-on experiences in effective learning - the elements that are required in digitalizing competence development.

In developing digital learning solutions, many managers and trainers seldom separate the development of supply-side (software and courses) from the development of demand-side (new learning practices and motivation). For example, the learning solutions can be "technically right", but they nevertheless fail to answer the actual questions of learners. In addition to this, learning cannot be separated from work or usage context - it cannot be restored to the learning portals or platforms. Therefore, in designing learning solutions, more emphasis should also be put on the learning solutions' ability to work as performance support systems and tools of social knowledge construction.

The learning content must lead the learners' cognitive and emotional processes. Focus should be on the integration of knowledge into real cases and situations. According to the theories of cognitive psychology (Anderson, Reder \& Simon, 1996), learning is most effective when we combine abstract instruction with concrete illustration; the same method works in the digital world as well.

\section{CONCLUSIONS}

It is much easier to digitalize the formal learning processes than to encourage informal learning at the workplace. Competence development must not be seen as the mere sharing of knowledge; rather, real knowledge is gained through learning and work processes. It is not uploading to the corporate intranet hundreds of "electronic manuals" containing essential information.

The essential factor in learning solutions is their usability and applicability to teaching and learning processes and, above all, their applicability to support work processes. The supply for learners is very easy to produce, but it is a much larger job to cause a change in the learning culture and to create real demand and motivate learning in the business units.

The pedagogical quality and relevance of content, the coaching of HRD personnel, the definition of strategy and its operative processes, the involvement of managers and the building of successful business cases are 
all essential factors in digitalizing competence development in the knowledge-intensive companies.

\section{REFERENCES}

Alamäki, A. (2000). Technological reasoning as a human side of technological innovation. In I. Mottier \& M. J. deVries (Eds.), Innovation and diffusion in technology education: Proceedings of PATT-10 conference (pp. 9-15). Eindhoven: PATT-Foundation.

Alamäki, A. \& Luukkonen, J. (2002). eLearning - digital means of competence development: strategies, content production, technologies and implementation. Helsinki: Edita.

Anderson, J., Reder, L. \& Simon, H. (1996). Situated learning and education. EducationalResearcher, 25(4), 5-11.

Argyris, C. (1992). On organizational learning. Cambridge: Blackwell.

Bell, D. (1976). The coming of post-industrial society. A venture in social forecasting. New York: Basic Books.

Hutchins, E. (1995). Cognition in the Wild. Cambridge, MA: MIT Press.

Lave, J. (1988). Cognition in practice. Mind, mathematics and culture in everyday life. New York: Cambridge University Press.

Masie, E. (2002). Blended learning: The magic is in the mix. In A. Rossett (Ed.), The ASTD e-learning handbook. Best practices, strategies, and case studies for an emerging field. (pp. 58-63). New York: Mc Graw Hill.

Rosenberg, M. (2001, Sep 30). Building a successful e-learning strategy. Paper presented at the Online Learning conference, Los Angeles, USA.

Senge, P. (1990). The fifth discipline: The art \& practice of the learning organisation. NewYork: Currency Doubleday.

Tuomi, I. (2002). The future of knowledge management. Lifelong Learning in Europe, 7(2), 69-79.

Weill, P. \& Broadbent, M. (1998). Leveraging the new infrastructure: How market leaders capitalize on IT. Boston, MA: Harvard Business School Press.

\section{BIOGRAPHY}

Ari Alamäki (Ed.D) works as senior consultant in e-learning and Kalle Mäkinen (M.Ed) works as a pedagogical concept designer in TietoEnator Corporation, Finland. 